\title{
Correlation of scar localization between cardiac magnetic resonance imaging and electro- anatomic mapping at electrophysiology study in patients with cardiac rhythm management devices
}

\author{
Rajeev R Fernando ${ }^{2 *}$, Nisreen F Ali ${ }^{2}$, Lara Bakhos ${ }^{2}$, Jeffrey R Winterfield ${ }^{2}$, David Wilber ${ }^{2}$, Osamah Abdallah', \\ Mark Rabbat ${ }^{2}$, Mushabbar A Syed ${ }^{2}$
}

From 18th Annual SCMR Scientific Sessions

Nice, France. 4-7 February 2015

\section{Background}

Cardiac magnetic resonance imaging (CMR) can accurately delineate myocardial scar for substrate guided ventricular tachycardia (VT) ablation. Susceptibility artifact from cardiac rhythm management device (CRMD) generator and leads can significantly affect image quality limiting the evaluation of myocardial scar and foci of VT. We conducted a retrospective study to correlate scars from CMR to the voltage mapping obtained at electrophysiology study (EPS).

\section{Methods}

We studied 27 patients with CRMD who underwent CMR and EPS at Loyola University Medical Center between $11 / 2012$ to $9 / 2014$. Baseline demographics and clinical parameters are outlined (Table 1). A total of 432 left ventricular (LV) segments were analyzed for wall motion and late gadolinium enhancement using the AHA 17 segment model excluding the apical cap. The presence of right ventricular (RV) scar and wall motion abnormalities was also recorded. Data from the EPS included the type of access (endocardial and/or epicardial), the presence and location of scar, and the VT foci.

\footnotetext{
${ }^{2}$ Department of Cardiology, Loyola University Medical Center, Maywood, IL, USA
}

Full list of author information is available at the end of the article

\section{Results}

Of the $432 \mathrm{LV}$ segments, 127 (29.3\%) were affected by artifact precluding assessment for myocardial scar. The mid anterior (81.4\%) and basal inferior (3.7\%) segments were the most and least affected by artifact respectively. CMR scar parameters were compared with EPS scar mapping (Table 2). CMR was able to identify LV scar, particularly endocardial scar, in most cases despite the presence of device-related artifact. In 17/22 patients (77.3\%) with CMR identified LV scar, the LV endocardial scar location on CMR was comparable to the voltage map at EPS. In only one patient was LV endocardial scar missed on CMR in a non-evaluable segment due to artifact, although that segment did have a wall motion abnormality. Exclusion of LV endocardial scar by CMR is associated with a low diagnostic yield of endocardial mapping at EPS. In 18/22 (81.8\%) patients with inducible VT, the focus of VT arose from an area delineated as scar on CMR. In the remaining 4 patients, only one patient had inducible VT unrelated to MRI scar. Of the ten RV scars identified at EPS, only 4 were detected by DE-MRI.

\section{Conclusions}

CMR can be a valuable tool in localizing LV scar prior to EPS for ablation of VT. However, 29.3\% of LV segments are not evaluable due to artifact from device generator (anterior wall in 65.4\%). Regional wall motion 
Table 1 Baseline clinical parameters

\begin{tabular}{cc}
\hline Age (years) & $58.52+/-14.82$ \\
\hline Male/Female & $(25 / 2)$ \\
\hline Ischemic cardiomyopathy & $16(59 \%)$ \\
\hline Non-ischemic cardiomyopathy & $11(41 \%)$ \\
\hline Diabetes mellitus & $4(15 \%)$ \\
\hline Hypertension & $14(52 \%)$ \\
\hline Hyperlipidemia & $14(52 \%)$ \\
\hline Smoking & $10(37 \%)$ \\
\hline Body mass index (kg/m2) & $26.5+/-6.3$ \\
\hline Body surface area (m2) & $2+/-0.14$ \\
\hline Left Ventricular Ejection Fraction (\% +/- standard deviation) \\
\hline Left ventricular end-diastolic volume index (\% +/- standard deviation) \\
\hline Right Ventricular Ejection Fraction (\% +/- standard deviation) & $41.23+/-16.73$ \\
\hline Pacemaker/lCD & $133.45+/-14.2$ \\
\hline
\end{tabular}

Table 2 Comparison of MRI and EPS parameters

\begin{tabular}{|c|c|c|c|c|c|}
\hline CMR parameter & EPS parameter & Co-efficient of correlation & P-value & $95 \%$ confidence interval for $r$ & Sample size \\
\hline CMR-All LV scar & EPS-All LV scar & 0.59 & $p<0.0025$ & $0.24-0.8$ & 24 \\
\hline CMR-LV endocardial scar & EPS-LV endocardial scar & 0.83 & $p<0.0001$ & 0.64-0.92 & 24 \\
\hline CMR-LV epicardial scar & EPS-LV epicardial scar & 0.65 & $p=0.078$ & $-0.09-0.93$ & 8 \\
\hline CMR-LV wall motion abnormality & EPS-LV endocardial scar & 0.49 & $p=0.0092$ & $0.14-0.73$ & 27 \\
\hline CMR-RV scar & EPS-RV scar & 0.57 & $p=0.0031$ & $0.22-0.79$ & 24 \\
\hline CMR-RV wall motion abnormality & EPS-RV scar & 0.42 & $p=0.028$ & $0.05-0.69$ & 27 \\
\hline
\end{tabular}

abnormalities in non-evaluable left and right ventricular segments can guide identification of scar at EPS.

\section{Funding}

None.

\section{Authors' details}

'Department of internal medicine, Loyola University Medical Center,

Maywood, IL, USA. ²Department of Cardiology, Loyola University Medical

Center, Maywood, IL, USA.

Published: 3 February 2015

doi:10.1186/1532-429X-17-S1-P244

Cite this article as: Fernando et al:: Correlation of scar localization between cardiac magnetic resonance imaging and electro-anatomic mapping at electrophysiology study in patients with cardiac rhythm management devices. Journal of Cardiovascular Magnetic Resonance 2015 17(Suppl 1):P244

\section{Submit your next manuscript to BioMed Central} and take full advantage of:

- Convenient online submission

- Thorough peer review

- No space constraints or color figure charges

- Immediate publication on acceptance

- Inclusion in PubMed, CAS, Scopus and Google Scholar

- Research which is freely available for redistribution

Submit your manuscript at www.biomedcentral.com/submit 